\section{Alteration mapping for geochemical exploration in Niazgholi-Moshiran area,Using Aster data}

\section{NEGIN MANZELATI, SEYEDEH NARGES SADATI AND ALI LOTFIBAKHSH}

University of Mohaghegh Ardabili

Presenting Author: neginmnz93@gmail.com

Niaz Gholi-Moshiran region is located in the 1: 100000 of Lahroud in the northwest of Ardabil province. Geologically, most of the area is covered with Paleocene-Eocene rocks which consist of volcanic sections with andesite, tephrite and andesite trachyte parts which are observed along with andesitic-tephritic pillow lava. The main image analysis techniques in this study were false color combination and color composite ratio. Due to the presence of $\mathrm{Mg}-\mathrm{OH}$ bond, montmorillonite, kaolinite, muscovite and illite minerals (Index of phyllic and argillic alteration zones) show maximum reflection in band 4 of SWIR and low reflection in band 6(due to the presence of Al-OH bond), so in the color combination of 468 , argillic and phyllic alterations are red to pink and propylitic alterations are green because of high reflection of index minerals (chlorite and epidote) in band 5 and 6 beside of low reflection in band 8(due to the presence of $\mathrm{Mg}-\mathrm{OH}$ bond)( FIG1). Also the color composite ratio method (bands $4 / 5,9 / 8,5+7 / 6$ respectively in RGB) was used to highlight alteration mapping (the argillic in red, propylitic in green and phyllic in blue)(FIG2).

FIG1: Aster ratio image (bands $4,6,8$ in RGB)

FIG2: Aster ratio image (bands $4 / 5,9 / 8,5+7 / 6$ in RGB)

\section{Refrences:}

[1] S. K. Patra, M. Shekher, S. S. Solanki, R. Ramachandran, and R. Krishnsn,A technique for generating natural colour images from false colour composite images", International journal of Remote Sensing, vol. 27 . 2977-2989,2006

[2] F. A. Kruse, J. W. Boardman. A. B. Lefkoff, K. B. Heidebrecht, A. T. Shapiro, P. J. Barloon, and A. F. H. Goetz, "The Spectral Image Processing System (SIPS) - Interactive Visualization and Analysis of Imaging Spectrometer Data", Remote Sensing of Environment. 44:145-163,1993
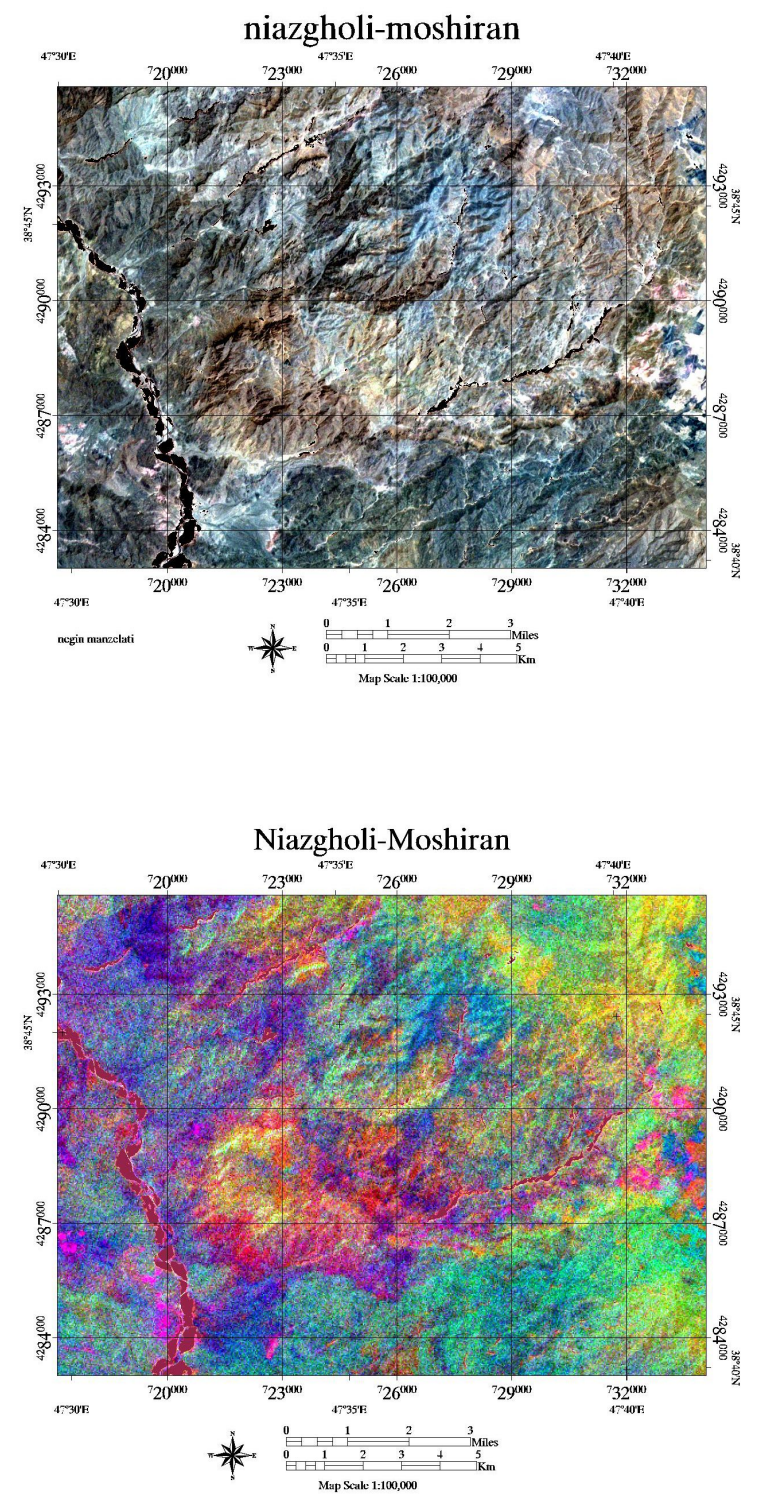